\title{
CLOSEST C-COMMAND, AGREE AND IMPOVERISHMENT: THE MORPHOSYNTAX OF NON-ACTIVE VOICE IN ALBANIAN*
}

\author{
DALINA KALLULLI ${ }^{\mathrm{a}}-$ JOCHEN TROMMER $^{\mathrm{b}}$ \\ ${ }^{a}$ Universität Wien/Institut für Sprachwissenschaft, Austria \\ ${ }^{\mathrm{b}}$ Universität Leipzig/Institut für Linguistik, Germany \\ Corresponding author: Dalina Kallulli, address: Sensengasse 3A, \\ A-1090 Wien, Austria, e-mail: dalina.kallulli@univie.ac.at
}

\begin{abstract}
We provide a minimalist syntactic analysis for the morphological realization of non-active voice in Albanian, a paradigm that exhibits a three-way alternation: inflectional affix, clitic and auxiliary choice. We show that the morphological realization of the Albanian non-active voice reflects the hierarchy of functional categories in the clause. More specifically, we argue that the distribution of the morphological means to realize non-active voice in this language is contingent on and regulated by two independently motivated morphosyntactic operations, namely Agree and Impoverishment, which are both governed in crucial respects by closest c-command.
\end{abstract}

Keywords: Agree, Albanian, Impoverishment, locality, non-active

\section{Introduction}

Alternations of synthetic (i.e., one-word) and periphrastic expressions of syntactic categories have become increasingly important for models of

* Some of the ideas contained in this paper were presented at the workshop 'The role of morphology in argument expression and interpretation' (Vienna, June 2005) and at the 2nd Budapest Generative Syntax Workshop (June 2009). We thank the audiences at these events for their questions and remarks. We are particularly grateful to Jim Wood and two anonymous reviewers for detailed comments and constructive criticism. We would also like to thank Stefan Schumacher for his close reading of section $\mathbf{2}$.

Kallulli's research was supported by an APART-fellowship from the Austrian Academy of Sciences. 
the morphology-syntax interface across modern linguistic theories. Two central areas in this field are alternations between affixes and clitics (Ortmann 2002; Woolford 2003), and alternations between affixes and auxiliary-participle constructions (Embick 2000; Sadler-Spencer 2001; Kiparsky 2005). As Kiparsky (2005) notes, paradigms combining such alternating forms have been especially relevant in the context of morphological blocking (McCloskey-Hale 1983; Andrews 1990; Poser 1992), particularly in non-lexicalist discussions, since they seem to challenge the lexicalist tenet that words and sentences are organized by distinct subsystems of grammar. A hot topic in this context has been the passive verb paradigm of Latin, which combines a synthetic and a periphrastic realization, and which has been discussed in the framework of Distributed Morphology (Embick 2000), in Paradigm Function Morphology (SadlerSpencer 2001), and in Lexicalist Morphology (Kiparsky 2005).

Against this background, in this paper, we discuss the expression of non-active voice in Albanian. Similar to Latin, Albanian has two distinct voice conjugational paradigms, namely active and non-active (Marantz 1984; Hubbard 1985; Massey 1991; Kallulli 1999; Manzini-Savoia 2007). ${ }^{1}$ The Albanian non-active conjugation displays an even more complex alternation than the Latin passive conjugation, employing three distinct linguistic means, namely: (i) affixation, as shown in (1a); (ii) cliticization, as shown in (1b); and (iii) auxiliary choice, as shown in (1c), which contrasts with its active counterpart in (1d) in terms of choice of the auxiliary. ${ }^{2}$

${ }^{1}$ The non-active voice is similar in its syntactico-semantic scope to the passive conjugation in Latin, or the non-active conjugation in Modern Greek, in that it is used not only with passive verbs, but also with reflexives, middles, unaccusatives and deponents (see, e.g., Embick 1997 and references therein for Latin and Greek, and Kallulli 2006; 2007 for Albanian). In other words, while the active form of a verb such as thaj 'I dry' means 'I dry stuff', its non-active form may have several meanings, including the following: 'I dry (myself)', 'I am being dried (by someone else)', 'I am dryable', 'I am easy to dry', 'I dry (e.g., in the sun)'. Such (voicerelated) syncretisms are also familiar from better studied languages like German and Romance, which in spite of lacking full voice paradigms use a pronoun or clitic in (some of) the same syntactic contexts (Grewendorf 1989; Grimshaw 1982).

2 The following abbreviations are used (e.g. in the glosses): aor (aorist), act (active voice), nact (non-active voice), adm (admirative mood), imper (imperative mood), opt (optative mood), imp (imperfect tense), pr (present tense), nom (nominative case), part (participle), prog (progressive aspect), sg (singular number), pl (plural number), subj (subjunctive mood), 1 (first person), 2 (second person), 3 (third person). 
(1) (a) Fëmija po lahet.

child.thenom prog wash.nact.3sg,pr

(i) 'The child is washing itself.'

(ii) 'The child is being washed.'

(b) Fëmija $*(\mathbf{u})$ la.

child.the nom nact wash.aor.3sg

(i) 'The child washed itself.'

(ii) 'The child was washed (by someone else).'

(c) Fëmija ishte larë.

child.thenom was.3sgnact wash.part

(i) 'The child had washed itself.'

(ii) 'The child had been washed (by someone else).'

(d) Fëmija kishte larë.

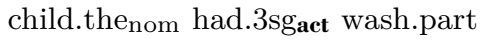

'The child had washed (stuff).'

Crucially, this three-way morphological alternation (i.e., affix, clitic and auxiliary choice) is determined by the broader morphosyntactic context in which the non-active occurs. Specifically, auxiliary selection, namely the Albanian counterpart of the verb 'to be', is used if the clause contains a Perfect form; the affix is used if the clause contains a Tense form other than the Aorist, but not Admirative, Optative or Imperative mood; and the clitic $u$, arguably derived from the Indo-European sue (Demiraj 1986), is used in all other contexts. ${ }^{3}$

This paper is organized as follows. In section $\mathbf{2}$, we present some preliminaries on the Albanian verbal system as well as our basic assumptions concerning the clause structure of Albanian. In section $\mathbf{3}$, we then propose a minimalist syntactic analysis of the Albanian non-active data. We contend that all aspects of the Albanian non-active exponence derive from two independent core mechanisms of morpho-syntax, Agree and Impoverishment, which are both governed in crucial respects by the notion of closest c-command. In section $\mathbf{4}$, we evaluate the merits of our analysis by comparing it against the account proposed in Rivero (1990). We conclude that our analysis is superior to Rivero's both on empirical and theoretical grounds.

3 Traditional descriptive grammars of Albanian treat Aorist as a tense; however, we think that it is more appropriate to treat it as an aspectual category (see section 2 for details on this point). 


\section{Albanian clause structure}

As is obvious from the description of the distribution of the non-active realization in section $\mathbf{1}$, Albanian has a complex system of tense, aspect and mood, involving three dimensions: basic tense (present vs. imperfect), perfectness (non-perfect vs. perfect) and aspect/mood.

A bird's eye view of the Albanian verbal system for first person singular forms is provided in Table 1 and Table 2, for the verb laj ' $\mathrm{I}$ wash' ${ }^{4}$ we omit Future, Imperative and participial constructions in these tables. ${ }^{5}$ Note in particular the (boldfaced) non-active markers in Table $2 .{ }^{6}$

Table 1

A bird's eye view of the Albanian verbal system - the active conjugation

\begin{tabular}{lllllll}
\hline & & \multicolumn{5}{c}{ Aspect and Mood } \\
\cline { 3 - 5 } Active & & Indicative & Subjunctive & Admirative & Optative & Aorist \\
\hline Non- & Present & la-j & të la-j & la-ka-m & la-fsh-a & la-v-a \\
\cline { 2 - 5 } Perfect & Imperfect & la-j-a & të la-j-a & la-kë-sh-a & & \\
\hline \multirow{4}{*}{ Perfect } & \multirow{2}{*}{ Present } & ka-m & të-ke-m & pas-ka-m & & \\
\cline { 2 - 5 } & & la-rë & la-rë & la-rë & pa-ç-a & pa-t-a \\
\cline { 2 - 5 } & Imperfect & ki-sh-a & të ki-sh-a & pas-kë-sh-a & la-rë & la-rë \\
& la-rë & la-rë & la-rë & & \\
\hline
\end{tabular}

The following clarifications are intended to help understand the system encapsulated in these tables.

Perfect forms consist of the corresponding non-perfect form of the auxiliaries kam 'I have' and jam 'I am' and the right-adjacent participle of the lexical verb. Non-active forms differ from active forms only by the choice of the auxiliary jam 'I am' instead of kam 'I have'. Aspect and mood cross-classify with simple tense (present and imperfect), except for the Optative and the Aorist (and the Imperative), which systematically

${ }^{4}$ The citation form of the Albanian verb is first person, singular number, active voice, indicative mood, present tense.

${ }^{5}$ Imperative only has two forms: 2nd person singular and 2nd person plural, of which the latter is homonymous with 2 nd person plural indicative.

${ }^{6}$ Recall from section $\mathbf{I}$ that the Albanian non-active paradigm employs three distinct linguistic means, namely affix, clitic, and auxiliary selection, depending on the broader morphosyntactic environment in which it occurs. 
Table 2

A bird's eye view of the Albanian verbal system - the non-active conjugation

\begin{tabular}{|c|c|c|c|c|c|c|}
\hline \multirow[b]{2}{*}{ Non-Active } & & \multicolumn{5}{|c|}{ Aspect and Mood } \\
\hline & & Indicative & Subjunctive & Admirative & Optative & Aorist \\
\hline \multirow{2}{*}{$\begin{array}{l}\text { Non- } \\
\text { Perfect }\end{array}$} & Present & la-he-m & të la-he-m & u la-ka-m & \multirow{2}{*}{ u la-fsh-a } & \multirow{2}{*}{$\mathbf{u}$ la-v-a } \\
\hline & Imperfect & la-he-sh & të la-he-sh-a & u la-kë-sh-a & & \\
\hline \multirow{3}{*}{ Perfect } & Present & ja-m & të je-m & qen-ka-m & \multirow{3}{*}{$\begin{array}{l}\text { qo-fsh-a } \\
\text { la-rë }\end{array}$} & \multirow{3}{*}{$\begin{array}{l}\text { qe-sh-ë } \\
\text { la-rë }\end{array}$} \\
\hline & 1 Iesent & la-rë & la-rë & la-rë & & \\
\hline & Imperfect & i-sh-a & të i-sh-a & qen-kë-sh-a & & \\
\hline
\end{tabular}

neutralize this contrast. Note that in line with Rivero (1990) and contrary to traditional descriptive grammars of Albanian, we view Aorist as a primarily aspectual category, not as tense. Unlike Imperfect, which represents a generic, habitual or repeated action, or an action in progress at a particular point in the past, Aorist represents an action that has taken place at a definite point or interval in the past, which is why it is also referred to as "Definite Past" (cf. Newmark et al. 1982; Rivero 1990). Imperfect is thus, as its name suggests, aspectually imperfective, whereas Aorist is aspectually perfective. Since Imperfect is aspectually analogous to present tense, it makes sense to treat the Aorist as an aspectual category, specifically contributing the perfective dimension, which can alternatively be contributed by perfect forms. ${ }^{7}$ Accordingly, the subdivison 'Imperfect' for the Perfect in the tables above simply indicates past tense, since the aspectual value in these cases, namely perfectivity, will be provided by the Perfect head (i.e., the auxiliary). In other words, 'Perfect Present' and 'Perfect Imperfect' differ simply in terms of their present versus past tense value, respectively (analogous to the opposition Present versus Past Perfect in English).

Turning to the specifics of the Albanian mood system, it is worth noting that both Admirative and Optative are formed via affixes that precede the person/number agreement morpheme. ${ }^{8}$ To illustrate, for first

${ }^{7}$ For further evidence highlighting the aspectual difference between Imperfect and Aorist in Albanian, see Kallulli (2006; 2007).

8 The admirative mood in Albanian is used to express a (speaker's) sense of surprise, doubt or dissent concerning an event that has taken place in the past or 
person singular (see Table 1 and Table 2), these are $-k a$ and $-k \ddot{e}$ for Admirative and $-f s h$ or its allomorphs $-c$ or $-s h$ for Optative. Subjunctive on the other hand is different from Admirative and Optative since it is invariably signaled by a dedicated particle, namely të, which appears quite high in the structure of the clause, preceding even clitics (for details, see Newmark et al. 1982; Rivero 1990; Kallulli 1995). ${ }^{9}$

Finally, note that the participle is the non-finite form of the verb in Albanian (i.e., the verb form that does not reflect the person and number of its subject). However, the non-finite constructions using it as their base (these are the so-called "privatives" like pa larë "without washing', gerundives like duke larë 'washing', infinitives like për të larë 'to wash', and absolutives like me të larë 'by washing/having washed') are all marked for voice, which highlights yet again the fact that voice is a major category of the Albanian verbal system. ${ }^{10}$

Following in all essential respects Rivero (1990), we assume that Albanian has the clause structure in (2).

(2) [Clitic $\left[\right.$ Tense ${ }_{\text {pr/imp }}\left[\right.$ Aspectaor $_{\text {Mood }}$ adm/opt/imper $[$ Perfect [Non-Active V]]]]]

The only two minor adjustments to Rivero's implementation derive from our theoretical assumptions: First, where Rivero assumes an independent agreement projection hosting clitics, we follow standard minimalist practice in locating agreement morphology in Tense and assume a separate Clitic projection above Tense (the position assumed by Rivero for

is taking place at the moment of speaking. Admirative is thus (compatible with) a factive proposition and may also occur in embedded clauses. The only case where it seems to function as an evidential is when it occurs within the scope of the future operator (realized as a particle high up in the structure of the clause, preceding clitics), which is also used to express irrealis.

${ }^{9}$ Simultaneously, for the second and third person singular in the present tense the verb in the subjunctive mood carries special inflectional morphology (which is however only minimally different from the indicative). This is illustrated in (i) below:

(i) Ana filloi të më lexojë letrën.

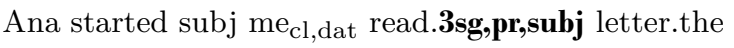

'Anna started to read me the letter.'

${ }^{10}$ As follows from the description of non-active voice realization in section $\mathbf{1}$, the non-active marker in these constructions is the clitic $u$-hence: pa $\boldsymbol{u}$ lare 'without being washed', duke u larë 'being washed', për t'u larë 'to be washed', and me t'u larë 'by being washed/having been washed'. 
Agr), à la Sportiche (1996). Second, Rivero assumes that Voice appears in the same structural position as Mood/Aspect (not below it), but requires that the Voice exponent be adjacent to the V. Since minimalist assumptions have eliminated S-structure and a fortiori S-structure constraints, we translate this into the assumption that the Voice head always merges with the bare verb root, whereas Mood/Aspect (when present) are located higher in the tree. ${ }^{11}$

Crucially, we have assumed with Rivero (1990) that Aspect and Mood occupy, or compete for, the same structural position. ${ }^{12}$ While we cannot dwell on this issue here, the fact that the (relevant) moods (i.e., Admirative, Optative and Imperative) are aspectually 'defective', in the sense that they do not have Aorist forms, or the opposition between Aorist and Imperfect, amounts to evidence for conflating Aspect and Mood in terms of syntactic distribution in the structure of the clause. ${ }^{13}$ Interestingly though, unlike Optative and Imperative, which in view of their irrealis semantics cannot be thought of as compatible with perfectivity, Admirative (which unlike Optative and Imperative has tense distinctions) is always aspectually perfective. We assume that this must be due to its factive meaning ingredient as well as the way the admirative forms are built, which by hypothesis is what derives its meaning (see also footnote 8). ${ }^{14}$ The very fact that Admirative is aspectually perfective in spite of lacking Aorist forms is evidence for the conflation of Aspect and Mood on the one hand and for the idea that Aorist is an aspectual category on the other.

Having presented the relevant preliminaries on the Albanian verbal system and our basic assumptions about the Albanian clause structure, in the next section we lay out our analysis of the morpho-syntax of non-active voice in this language.

${ }^{11}$ Note that in line with Rivero (1990), we assume that the Subjunctive particle is not merged in Asp/Mood but in a higher position in the structure of the clause, preceding clitics (see Kallulli 1995 for details). This also applies to the particles signaling the non-finite constructions based on the participle mentioned earlier. This assumption is fully legitimized by morpheme ordering; crucially, the respective particles in all these constructions precede clitics (see also footnotes 9 , 10 for some illustrations).

12 This idea is reminiscent of Laka's (1990) $\Sigma$ P, a (broader) syntactic category one of the instantiations of which is NegP.

${ }^{13}$ For Optative and Imperative this may of course be a consequence of their tense defectiveness mentioned earlier.

14 The Admirative affix is historically derived from the auxiliary kam 'I have', which is also used to build Perfect. 


\section{Analysis: Agree and Impoverishment}

In our analysis we show that all aspects of Albanian non-active exponence derive from two independently motivated core mechanisms of morphosyntax, Agree and Impoverishment, which are both governed in crucial respects by the notion of closest c-command.

Given the inventory of functional elements for which we argued in the previous section (a clause contains Tense if its verb form is distinctive for Present vs. Imperfect), the distribution of the different means to realize non-active voice follows the complex default pattern in (3). (Recall that Optative and Imperative forms do not contrast for Present versus Imperfect, which we take to mean that they lack Tense.)

(3) Distribution of non-active realization

1. If the clause contains Perfect:

express Non-active by choice of the auxiliary

2. Else: If the clause contains Tense but not Admirative: express Non-active by an inflectional affix

3. Else: express Non-active by a clitic

Thus, a simple imperfect non-active form like lahesha 'I was being washed' uses a non-active affix by clause 2 of (3) since it does not involve a Perfect head, whereas a perfect form such as isha larë 'I was washed' involves auxiliary selection (cf. the active form kisha larë 'I had washed (stuff)') by clause 1, even though it is also specified for imperfect Tense (cf. jam larë 'I am washed' with Perfect, but present tense). Non-finite forms but also non-perfect Optative (and Imperative) forms (u lafsha 'may I be washed'), Perfect Optative forms (qofsha larë 'may I have been washed') show again that clause 1 has precedence over clause 2 .

Given the clause structure in (2), as discussed in the previous section and repeated below for ease of reference, and the correspondence in (4), the complex and apparently arbitrary statement in (3) reduces in virtually all respects to the syntactic generalization in (5): ${ }^{15}$

(2) $\quad\left[\right.$ Clitic $\left[\right.$ Tense $_{\text {pr/imp }}\left[\right.$ Aspect $_{\text {aor }} /$ Mood $_{\text {adm/opt/imper }}[$ Perfect [Non-Active V]]]]]

${ }^{15}$ We discuss complications with Admirative forms in detail further down in this section. 
(4) Auxiliary Non-active $\rightarrow$ Perfect

Affixal Non-active $\rightarrow$ Tense

Clitic Non-active $\rightarrow$ Clitic

(5) The Non-active head is expressed by the closest suitable head (Perfect, Tense, Clitic) which c-commands it

Let us illustrate (5) with a few examples: (6) shows why a perfect form such as isha larë 'I was washed' expresses non-active by Auxiliary choice (i.e., in the Perfect head). All three heads (Clitic, Tense and Perfect) c-command the Non-active head (indicated by connecting lines), but Perfect is closer to Non-active than Tense and Clitic are, rendering the c-command relation between Clitic/Tense and Non-active irrelevant (indicated by the $* \operatorname{sign})$. This situation corresponds to clause 1 of $(3)$.

(6) $\quad[$ Clitic ... [Tense [Admirative [Perfect [Non-Active V]]]]]

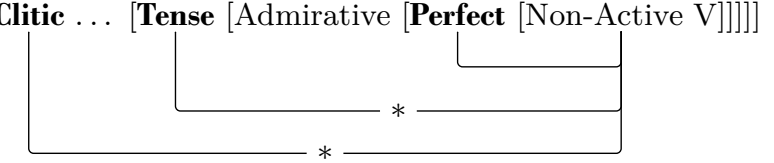

(7) illustrates the case of a Non-active form which specifies Tense, but not Perfect, such as the imperfect form lahesha 'I was being washed'. Non-active is c-commanded by Tense and the Clitic head, but is realized by the Tense head (i.e., as an affix) because the latter is below the Clitic head in the functional syntactic structure (cf. clause 2 of (3)):

(7)

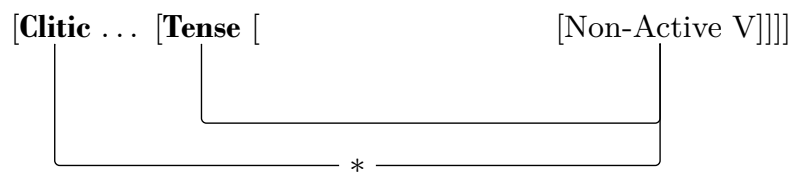

(8) shows the case of an imperative or simple (i.e., non-perfective) optative non-active form (e.g., u lafsha 'may I be washed'). Non-active is realized in the Clitic position because this is the only c-commanding head out of the set of relevant heads $\{$ Clitic, Tense, Perfect $\}$ which is above it (cf. clause 3 of (3)):

(8) [Clitic ... [Optative/Imperative [

Non-Active V]]]] 
However, while the generalization in (5) is successful in restating the arbitrary algorithm in (3) in well-motivated syntactic terms, it still does not explain how this algorithm becomes effective in the syntactic system of Albanian. In what follows, we show that it can be straightforwardly derived by a standard version of Agree which is the core operation of Minimalist Grammar (Chomsky 2000; 2001). In particular, we adopt the version of Agree in (9) proposed by Pesetsky-Torrego (2004; 2006; 2007) because it is especially clear and formally explicit:

(9) Agree

1. At Merge an uninterpretable/unvalued feature $\mathbf{F}_{\mathbf{u}}$ matches the closest interpretable feature $\mathbf{+} \mathbf{F}_{\mathbf{i}}$ in its c-command domain

2. $\mathbf{F}_{\mathbf{u}}$ is valued by $+\mathbf{F}_{\mathbf{i}}$

3. $\quad+\mathbf{F}_{\mathbf{i}}$ gets unvalued (deactivation)

The only assumption we make in addition to (9) is that specific functional heads of Albanian (namely Clitic, Tense, and Perfect) are specified by the uninterpretable/unvalued non-active feature $\mathrm{NA}_{\mathrm{u}}$. This assumption is completely parallel to the claim that in cases of standard verb-subject agreement, clausal Tense is specified for unvalued person-number features which trigger valuing by the subject and lead to displaced realization of these features on verbs. Similarly, in our analysis the displaced spellout of non-active on clitics and auxiliaries follows from the fact that the corresponding functional heads are specified by non-active in the functional lexicon of Albanian.

We illustrate the functioning of (9) for the perfect form isha larë 'I was washed' (cf. (6)) in (10). In the first step after combining the verb root and Non-active, which is of course interpretable and specified/valued as $+\mathrm{NA}_{\mathrm{i}}$, Perfect is merged to the resulting complex (10a). Match identifies the $+\mathrm{NA}_{\mathrm{i}}$ of the Non-active head as an appropriate target for the unvalued $\mathrm{NA}_{\mathrm{u}}$ of the perfect head (10b), Value copies the "+" value to the Perfect head (10c) and the original $+\mathrm{NA}_{\mathrm{i}}$ of the Non-active head becomes deactivated (loses its "+" value), (10d). The newly created $+\mathrm{NA}_{u}$ on the perfect head is later spelled out by a specific choice of auxiliary (see sections $\mathbf{1}$ and $\mathbf{2}$, especially Table 1 and Table 2 for details).

An apparent problem for our analysis emerges if we consider the full structure of isha larë, which instantiates a superstructure of (10) adding Tense on top of it, resulting in (11). 
(10) Deriving the realization of Non-active through auxiliary selection

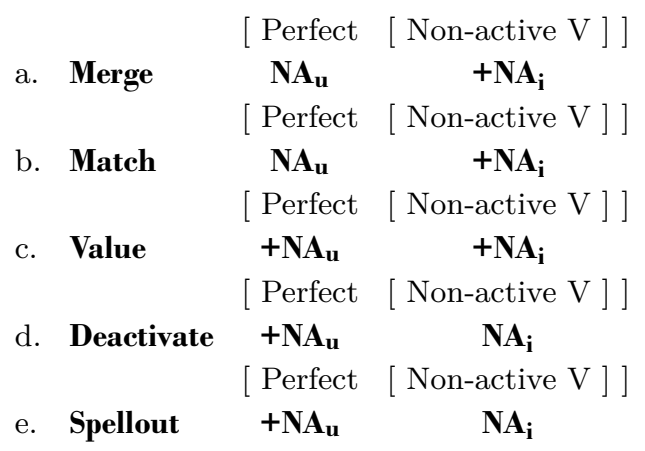

(11) Tense [ Perfect [ Non-active V ]] $\mathrm{NA}_{\mathrm{u}}+\mathrm{NA}_{\mathrm{u}} \quad \mathrm{NA}_{\mathrm{i}}$

While $\mathrm{NA}_{\mathrm{i}}$ is interpretable to semantic interpretation at $\mathrm{LF}$, and $+\mathrm{NA}_{\mathrm{u}}$ to morphological spell-out at PF, $\mathrm{NA}_{\mathrm{u}}$ on Tense will not enter any Agree relation because there is no $+\mathrm{NA}_{\mathrm{i}}$ left below it, and will potentially lead to the crash of the derivation. ${ }^{16}$ This is where Impoverishment enters the picture. We adopt Béjar's (2003) position, who shows convincingly that unvalued uninterpretable features do not necessarily lead to ungrammaticality in assuming that these features may be deleted by inner-syntactic Impoverishment rules. ${ }^{17}$ More specifically, we propose for Albanian the rule in (12), which deletes an unvalued uninterpretable NA feature if it is c-commanded by any other head:

(12) $\mathrm{NA}_{\mathrm{u}} \rightarrow \emptyset /[\ldots[-$

We assume that impoverishment rules apply in syntax whenever their target and context restrictions are met, and do not fully delete features, but simply render them invisible to the morphosyntactic computation (indi-

16 Thus, in our system a goal with a valued feature is active until it values a probe.

17 While the original conception of impoverishment (Halle-Marantz 1993) locates it in the post-syntactic morphology, Béjar (2003) and Keine (2010) provide strong evidence that at least an important subset of impoverishment rules applies in syntax with important consequences for argument encoding in complex agreement and case systems. Note however that our proposal is more in the vein of Keine (2010) than Béjar (2003), since in Béjar's system failure to value an unvalued feature is tolerated only if an attempt is made to Probe with no matching goal in the search space. 
cated in what follows by strikethrough). Hence, interpretable features are still accessible to semantic interpretation at LF after being impoverished.

Given these assumptions, (12) will reduce (11) to (13) whichever head is merged next, literally eliminating the problem of orphaned unvalued features. Obviously, the same rule will also account for the deletion of superfluous $\mathrm{NA}_{\mathrm{u}}$ in Clitic heads for forms where the interpretable NA feature has already been used up by one of the heads below it.

$$
\left[\begin{array}{ccc}
\text { Head [ Tense } & {[\text { Perfect }} & \text { [ Non-active V ] ] } \\
& \mathrm{NA}_{\mathrm{u}} & \mathrm{NA}_{\mathrm{i}}
\end{array}\right.
$$

Under the assumption that the heads Clitic, Tense and Perfect in Albanian are generally specified for unvalued NA, the analysis developed so far derives the correct distribution for clitics, affixes and auxiliaries for all cases except for simple admirative forms. As shown in Table 1 and Table 2 in section 2, Admirative in Albanian has a Tense head, therefore we predict that it should realize non-active by means of an affix, but in fact, it uniquely invokes the clitic u (cf. u lakësha 'so I was washed!'). (14) illustrates this problem: at the point where Tense is merged above Admirative, its unvalued NA feature should match the $+\mathrm{NA}$ of the Non-active head and be valued by it, ultimately resulting in the spellout by the affix $-(h) e$ : (14)
$\underset{\mathrm{NA}_{\mathrm{u}}}{[}$

Thus, in the context of Admirative, Tense behaves as inert with respect to the syntactic presence of Non-active. We propose that this exceptional behavior of Tense is also derived straightforwardly from impoverishment, namely from the rule in (15), which deletes an unvalued NA feature when the head hosting the feature c-commands (or is c-commamnded by) an Admirative head:

(15) $\mathrm{NA}_{\mathrm{u}} \rightarrow \emptyset /$ Admirative

Recall that impoverishment applies in the syntactic derivation whenever its target and context restrictions are met. Now, at the point where syntactic computation reaches (14), (15) gets active, and reduces it to (16), blocking Agree of the Tense head with the Non-active head. 
(16) [ Tense [ Admirative [ Non-active V ]]] $+\mathrm{NA}_{\mathrm{i}}$

Instead, Clitic is merged resulting in (17):

(17) [ Clitic [ Tense [ Admirative [ Non-active V ]]]] $\mathrm{NA}_{\mathrm{u}} \quad+\mathrm{NA}_{\mathrm{i}}$

Under the assumption that context restrictions of morphological operations are subject to strict locality (Trommer 2002; Bonet-Harbour to appear), i.e., can only be located in the head $\mathrm{H}$ which a rule (potentially) targets for application, or the closest head c-commanded by $\mathrm{H}$ (or c-commanding it), the impoverishment rule in (15) will not affect the NA feature in the Clitic head of (17) since the admirative context is rendered invisible by the intervening Tense head. Consequently, the clitic $\mathrm{NA}_{\mathrm{u}}$ will match and value with the $+\mathrm{NA}_{\mathrm{i}}$ of the Non-active head, resulting correctly in the spell-out of Non-active by the clitic $u .{ }^{18}$ Again closest c-command proves to be the decisive notion which derives crucial aspects of the Albanian voice system.

Note finally that this analysis also predicts correctly that perfect admirative forms (e.g., qenkam larë 'so I have been washed!') will be spelled out by choice of auxiliary, not by the exceptional clitic, even though they instantiate both Tense and Admirative. Given the functional structure we have proposed, Admirative is still absent when Perfect is merged with [Non-active V], resulting in the syntactic configuration in (18):

(18) [ Perfect [ Non-active V ]]

$\mathrm{NA}_{\mathrm{u}} \quad+\mathrm{NA}_{\mathrm{i}}$

The impoverishment rule in (15) cannot apply here because there is no 'Tense' context yet, and hence Agree will shift the + value to the Perfect position, resulting after subsequent merge of Tense and Admirative in (19), which does not induce Agree because there is no instance of $+\mathrm{NA}_{\mathrm{i}}$.

(19) [ Tense [ Admirative [ Perfect [ Non-active V ]]]] $\mathrm{NA}_{\mathrm{u}}+\mathrm{NA}_{\mathrm{u}} \quad \mathrm{NA}_{\mathrm{i}}$

${ }^{18}$ Recall that impoverishment makes features invisible for morphosyntactic computation, thus $A_{u}$ in (17) is irrelevant for establishing closest c-command for the Agree operation. 
Turning to the non-finite constructions using the participle as their base (cf. section $\mathbf{2}$, footnotes 10 and 11), recall that by the statement in (3), it follows that in non-finite constructions non-active voice is realized as a clitic. This fact is straightforwardly derived under our analysis since these clauses lack Tense altogether.

We turn finally to the concrete spell-out of non-active by morphological formatives. We adopt Distributed Morphology (Halle-Marantz 1993), i.e., post-syntactic insertion of markers ("vocabulary items") into the heads delivered by syntax. Following common assumptions in Distributed Morphology, we assume that vocabulary insertion deletes the features which it targets, but that there is potentially multiple insertion of vocabulary items into single heads in so far as the relevant markers specify different target features, which may be "used up" by distinct markers. ${ }^{19}$

(20) shows the vocabulary items we assume as specific for non-active morphology:

(20) Vocabulary items for non-active formatives:
(a) $-\mathrm{e} \leftrightarrow+\mathrm{NA}_{\mathrm{u}} /[-]_{\text {Tense }}$
(b) $\mathrm{u} \leftrightarrow+\mathrm{NA} u /[-]_{\text {Clitic }}$

In Distributed Morphology there is no strict distinction between affixes, clitics and separate words; instead, there is "syntax all the way down". The apparent clitic and affix realization of Non-active are simply a consequence of different syntactic positions of $+\mathrm{NA}_{\mathrm{u}}$ in different constructions, and of context-sensitive spell-out. There simply is no evidence in Albanian that the traditional labels 'clitic' and 'affix' for the realization of Non-active are phonologically motivated.

Capturing the realization of $+\mathrm{NA}_{\mathrm{u}}$ by choice of auxiliary is a more complex problem. It is tempting to claim that the auxiliary jam 'I am' in Albanian works as a kind of portmanteau which marks Perfect and Non-active at the same time, whereas $\mathrm{kam}$ 'I have' is a simple 'marker' for perfectivity. However, this analysis would be highly problematic since jam 'I am' occurs in contexts where no Non-active is present (as is for

19 This corresponds to the notion of "feature discharge" in Noyer (1997) which has been labeled "fission" by Halle (1997) and Frampton (2002), although it differs substantially from the fission operation proposed in Halle-Marantz (1993). Here we presuppose the formalization of vocabulary insertion in Trommer (2003), where multiple insertion into the same head is not further restricted by languagespecific parameters and templatic positions as in Noyer's original proposal. 
instance the case when it is used as a copula, on a par with 'to be' in English), and stipulating that 'to be' is more complex than 'to have' conflicts with the cross-linguistically well-motivated observation (Kayne 1993) that 'to have' often functions as a conglomerate of 'to be' with additional functional structure such as an incorporated local preposition.

Here we will maintain that the standard analysis of the relation between 'to be' and 'to have' is essentially correct, and that the distribution of both auxiliaries in the Albanian voice system is another consequence of impoverishment (see Lahne 2008 for a related analysis of spell-out crucially triggered by syntactic movement and impoverishment). Since the details of the functional decomposition for auxiliaries are immaterial to our concerns, we will simply assume that 'to have' has the structure [Perfect $\mathrm{NA}_{\mathrm{u}} \mathrm{P}$ ] (where $\mathrm{P}$ stands for whatever features distinguish 'to be' and 'to have') and 'to be' is just [Perfect $\mathrm{NA}_{\mathrm{u}}$ ]. In particular, we assume the vocabulary items in $(21):{ }^{20}$

(21) Vocabulary items for auxiliaries

(a) ja $\leftrightarrow[$ Perfect $]$

(b) $\mathrm{ka} \leftrightarrow[$ Perfect P]

The crucial realization of Non-active in the Perfect head is now achieved indirectly by the impoverishment rule in (22), which deletes $\mathrm{P}$ in the context of an uninterpretable Non-active feature:

(22) $\mathrm{P} \rightarrow \emptyset /[-$ Perfect $+\mathrm{NA}$ u

By assumption, Perfect forms in Albanian generally involve the complex head [Perfect $\mathrm{NA}_{\mathrm{u}} \mathrm{P}$ ], which consistently shows up in all active forms. However, as soon as the clause is non-active, the uninterpretable $\mathrm{NA}_{\mathrm{u}}$ feature of the Perfect head will trigger Agree with the Non-active head valuing $\mathrm{NA}_{\mathrm{u}}$ to $+\mathrm{NA}_{\mathrm{u}}$, which in turn triggers (22) and leads to exceptional insertion of (21a).

In sum, we have argued that the morphological realization of Albanian non-active voice reflects hierarchical relations of functional categories in the clause and is sensitive to syntactic locality in a rather transparent way.

\footnotetext{
${ }^{20}$ Neglecting potential allomorphs, note that vocabulary items may be underspecified, therefore $(21 b)$ is inserted into the more specific [Perfect $\left.+\mathrm{NA}_{u} \mathrm{P}\right]$.
} 
The morphological realization of non-active voice in Albanian has also been discussed in Rivero (1990). In the next section, we present Rivero's analysis, comparatively evaluating it against our own.

\section{Rivero (1990)}

Rivero's account of the morphological realization of non-active voice in Albanian invokes two constraints: First, the purely morphological constraint stipulating that the Albanian verb may carry maximally three suffixes (we will call this the "3-affix constraint") and second, an adjacency requirement which demands that Voice must be adjacent to the verb in syntactic S-structure (the "adjacency requirement"). Rivero assumes the phrase structure in (23), which is in most respects the one we have adopted here (see section $\mathbf{2}$ for discussion):

$$
\text { [AgrP }[\text { Person, Number] [TP [ } \pm \text { Past }][\mathrm{XP}[\text { Voice/Mood/Aspect] [VP V]]]] }
$$

Crucially, the 3-affix-constraint refers to abstract (pre-spellout) heads.

Thus, an indicative non-active form such as lah-e-sh-a 'I was being washed' which has the structure [[[V Voice] +Past $]$ Agr $]$ after headmovement, is exactly at the upper limit of three affixes and may therefore realize Non-active as an affix. On the other hand, an optative non-active form using an affix would have the structure [[[[V Voice] Opt] +Past $]$ Agr], which is with four affixes too complex for the constraint and therefore uses a clitic instead ( $u$ la-fsh-a 'may I be washed'). The same treatment extends to the aorist and the admirative, which by assumption also contains two layers (tense and aspect) in addition to Non-active and agreement.

In all these forms (cf. again la-he-sh- $a$ and $u l a-f s h-a$ ) the adjacency requirement is obviously satisfied because the Non-active exponents $u$ and $-e$ are left- or right-adjacent to the verb root. On the other hand, periphrastic/perfect forms bring with them the problem that the auxiliary intervenes between the lexical verb root and a potential clitic realization of Non-active. Thus, the Non-active corresponding to active kam larë 'I have washed' cannot be *u kam larë (recall that clitics in Albanian indicative clauses always precede the finite verb or auxiliary), which would violate the adjacency requirement since $u$ is not adjacent to (the participle) larë. Therefore, under Rivero's account, in these cases the auxiliary itself lexicalizes Non-active. Since auxiliaries in Albanian compound tenses are systematically left-adjacent to the corresponding 
participle, this satisfies the adjacency requirement (and the 3-affix constraint because neither lexical verb nor auxiliary carry more than 3 affixes).

Though Rivero's analysis reveals important generalizations about the Albanian Non-active system, it faces a number of technical and conceptual problems: First, as explicitly acknowledged by Rivero, her analysis does not account for the fact that periphrastic forms (and more generally, participles) in Albanian do not express Non-active by an affix. Thus, the hypothetical Non-active form * $k a-m$ la-he-r would satisfy both the 3-affix constraint and the adjacency requirement. Second, it is not really clear what the adjacency requirement exactly requires. It cannot literally stipulate that the head expressing non-active must be linearly adjacent to the head root because in the grammatical form ja-m la-rë 'I am washed', the 1st person singular affix $-m$ intervenes between the lexical verb root $l a$ - and the auxiliary stem $j a-$, which according to Rivero expresses Non-active in this form. Third, the 3-affix constraint is a highly stipulative assumption and cannot be derived independently under any theory that we are aware of.

We conclude therefore that our analysis (presented in section 3) is superior to Rivero's, since it obviates the assumption of stipulative morphological constraints and allows a unified analysis of constructions involving auxiliaries.

\section{Conclusion}

In this paper, we have shown that the morphological realization of Albanian non-active voice reflects the hierarchy of functional categories in the clause. Crucially, we have argued that the distribution of the morphological means employed to realize non-active in this language is contingent on and regulated by two independently motivated morphosyntactic operations, Agree and Impoverishment, which are both governed by closest c-command. Thus, morphology is sensitive to syntactic locality in a rather transparent way. 


\section{References}

Andrews, Avery 1990. Unification and morphological blocking. In: Natural Language and Linguistic Theory 8:507-57.

Béjar, Susana 2003. Phi-syntax: A theory of agreement. Doctoral dissertation, University of Toronto.

Bonet, Eulàlia - Daniel Harbour to appear. Contextual allomorphy. In: Jochen Trommer (ed.): The morphology and phonology of exponence. The state of the art. Oxford University Press, Oxford.

Chomsky, Noam 2000. Minimalist inquiries: The framework. In: Roger Martin-David Michaels - Juan Uriagereka (eds): Step by step: Essays on minimalist syntax in honor of Howard Lasnik, 89-155. MIT Press, Cambridge MA.

Chomsky, Noam 2001. Derivation by phase. In: Michael Kenstowicz (ed.): Ken Hale: A life in language, 1-52. MIT Press, Cambridge MA.

Demiraj, Shaban 1986. Gramatikë historike e gjuhës shqipe [Historical grammar of Albanian]. Shtëpia Botuese "8 Nëntori", Tiranë.

Embick, David 1997. Voice and the interfaces of syntax. Doctoral dissertation, University of Pennsylvania.

Embick, David 2000. Features, syntax, and categories in the Latin perfect. In: Linguistic Inquiry $31: 185-230$.

Frampton, John 2002. Syncretism, impoverishment, and the structure of person features. In: Papers from the Chicago Linguistics Society Meeting Vol. 38, 207-222. Chicago Linguistics Society, Chicago.

Grewendorf, Günther 1989. Ergativity in German. Mouton de Gruyter, Berlin \& New York.

Grimshaw, Jane 1982. On the lexical representation of Romance reflexive clitics. In: Joan Bresnan (ed.): The mental representation of grammatical relations, 87-148. MIT Press, Cambridge MA.

Halle, Morris 1997. Distributed morphology: Impoverishment and fission. In: Benjamin Bruening - Yoonjung Kang-Martha McGinnis (eds): Papers at the Interface (MIT Working Papers in Linguistics 30), 425-49. MIT Press, Cambridge MA.

Halle, Morris - Alec Marantz 1993. Distributed morphology and the pieces of inflection. In: Kenneth Hale-Samuel J. Keyser (eds): The view from building 20. Essays in linguistics in honor of Sylvain Bromberger, 111-76. MIT Press, Cambridge MA.

Hubbard, Philip 1985. The syntax of the Albanian verb complex. Garland, New York.

Kallulli, Dalina 1995. Clitics in Albanian (University of Trondheim Working Papers in Linguistics 24). University of Trondheim, Trondheim.

Kallulli, Dalina 1999. Non-active morphology in Albanian and event (de)composition. In: István Kenesei (ed.): Crossing boundaries: Advances in the theory of Central and Eastern European languages, 263-92. John Benjamins, Amsterdam \& Philadelphia.

Kallulli, Dalina 2006. Unaccusatives with dative causers and experiencers: A unified account. In: Daniel Hole-André Meinunger - Werner Abraham (eds): Datives and other cases, 271-301. John Benjamins, Amsterdam \& Philadelphia.

Acta Linguistica Hungarica 58, 2011 
Kallulli, Dalina 2007. Rethinking the passive/anticausative distinction. In: Linguistic Inquiry $38: 770-80$.

Kayne, Richard S. 1993. Toward a modular theory of auxiliary selection. In: Studia Linguistica $47: 3-31$.

Keine, Stefan 2010. Case and agreement from fringe to core: A minimalist approach. Mouton de Gruyter, Berlin \& New York.

Kiparsky, Paul 2005. Blocking and periphrasis in inflectional paradigms. In: Geert Booij-Jaap van Marle (eds): Yearbook of morphology 2004, 113-35. Kluwer, Dordrecht.

Lahne, Antje 2008. Where there is fire there is smoke: Local modelling of successivecyclic movement. Doctoral dissertation, Universität Leipzig.

Laka, Itziar 1990. Negation in syntax. Doctoral dissertation, MIT.

Manzini, M. Rita-Leonardo Savoia 2007. A unification of morphology and syntax: Investigations into Romance and Albanian dialects. Routledge, London.

Marantz, Alec 1984. On the nature of grammatical relations. MIT Press, Cambridge MA.

Massey, Victoria 1991. Compositionality and constituency in Albanian. Doctoral dissertation, University of North Carolina at Chapel Hill.

McCloskey, James - Kenneth Hale 1983. On the syntax of person-number inflection in Modern Irish. In: Natural Language and Linguistic Theory 1:487-533.

Newmark, Leonard-Philip Hubbard-Peter R. Prifti 1982. Standard Albanian: A reference grammar for students. Stanford University Press, Stanford.

Noyer, Rolf 1997. Features, positions and affixes in autonomous morphological structure. Garland, New York. (Revised version of 1992 MIT doctoral dissertation.)

Ortmann, Albert 2002. Kategorien des Nomens. Schnittstellen und Ökonomie. Niemeyer, Tübingen.

Pesetsky, David - Esther Torrego 2004. The syntax of valuation and the interpretability of features. Manuscript. MIT/University of Massachusetts.

Pesetsky, David - Esther Torrego 2006. Probes, goals and syntactic categories. In: Yukio Otsu (ed.): Proceedings of the Seventh Tokyo Conference on Psycholinguistics, 25-60. Hituzi Syobo, Tokyo.

Pesetsky, David - Esther Torrego 2007. The syntax of valuation and the interpretability of features. In: Simin Karimi-Vida Samiian-Wendy K. Wilkins (eds): Phrasal and clausal architecture. Syntactic derivation and interpretation, 262-94. John Benjamins, Amsterdam \& Philadelphia.

Poser, William 1992. Blocking of phrasal constructions by lexical items. In: Ivan A. Sag-Anna Szabolcsi (eds): Lexical matters, 111-30. CSLI Publications, Stanford, CA.

Rivero, Maria-Luisa 1990. The location of nonactive voice in Albanian and Modern Greek. In: Linguistic Inquiry $21: 135-46$.

Sadler, Louisa-Andrew Spencer 2001. Syntax as an exponent of morphological features. In: Geert Booij-Jaap van Marle (eds): Yearbook of morphology 2000, 71-96. Kluwer, Dordrecht. 
Sportiche, Dominique 1996. Clitic constructions. In: Johan Rooryck-Laurie Zaring (eds): Phrase structure and the lexicon, 213-76. Kluwer, Dordrecht.

Trommer, Jochen 2002. The post-syntactic morphology of the Albanian pre-posed article: Evidence for Distributed Morphology. In: Balkanistica 15 : 349-64.

Trommer, Jochen 2003. Feature (non-)insertion in a minimalist approach to spellout. In: Proceedings of the Chicago Linguistics Society 39:469-480.

Woolford, Ellen 2003. Clitics and agreement in competition: Ergative crossreferencing patterns. In: Angela Carpenter-Andries Coetzee-Paul de Lacy (eds): Papers in Optimality Theory II, 421-49. GLSA, Amherst. 